\title{
PENENTUAN DAERAH PENANGKAPAN MADIDIHANG (Thunnus albacares) DI PERAIRAN PROVINSI ACEH BERDASARKAN KOMPOSISI UKURAN PANJANG
}

\section{Determination of Fishing Ground of Yellowfin Tuna (Thunnus albacares) in The Waters of Aceh Province Based on Composition Long Size}

\author{
Oleh; \\ Samsul Bahri ${ }^{1 *}$, Wahyu Eka Sari ${ }^{2}$ \\ ${ }^{1}$ Lembaga Kajian Strategis dan Kebijakan Publik-LEMKASPA, Banda Aceh \\ ${ }^{2}$ Fakultas Kedokteran Hewan, Universitas Syiah Kuala, Banda Aceh \\ *Korespondensi: samsulbahri@apps.ipb.ac.id
}

\begin{abstract}
ABSTRAK
Tuna madidihang (Thunnus albacares) merupakan jenis tuna yang memiliki nilai ekonomis penting, dan termasuk ke dalam kelompok jenis pelagis besar, dengan siklus hidupnya berada di perairan tropis dan sub-tropis. Madidihang beruaya pada lintas perairan untuk mencari sumber makanan dan melakukan pemijahan. Populasi madidihang di perairan terancam akibat terjadinya degradasi daerah penangkapan. Hal ini disebabkan oleh penangkapan yang tidak terkontrol, sehingga mengakibatkan jumlah populasi madidihang yang terdapat di perairan Provinsi Aceh semakin mengecil pada ukuran panjang. Upaya dalam menjaga potensi madidihang di perairan Provinsi Aceh dengan menghitung komposisi ukuran hasil tangkapan berdasarkan waktu (temporal) dan daerah penangkapan (spasial), hal ini dapat menjadi langkah dalam menekan tingkat pemanfaatan sumberdaya madidihang belum layak tangkap secara besar-besaran. Metode dalam penelitian meliputi pengumpulan data primer dan data sekunder, serta análisis hasil tangkapan berdasarkan komposisi ukuran panjang untuk menentukan daerah penangkapan madidihang. Tujuan mengetahui komposisi ukuran panjang hasil tangkapan berdasarkan lokasi dan waktu penangkapan, agar dapat menentukan jenis alat tangkap yang dioperasikan untuk menghindari tertangkapnya ikan-ikan madidihang belum layak tangkap (ilegal size). Penentuan daerah penangkapan (fishing ground) madidihang secara spasial dan temporal dapat diinterpretasikan dalam peta daerah penangkapan. Optimasi penangkapan madidihang lebih efektif di perairan Pulau Aceh, Samudera Hindia, dan perairan Pulau Rondo.
\end{abstract}

Kata kunci: Daerah penangkapan ikan, Provinsi Aceh, , Thunnus albacares, tuna Madidihang

\begin{abstract}
Yellowfin tuna (Thunnus albacares) is a type of large pelagic species that has important economic value, with its life cycle in tropical and sub-tropical waters. Yellowfin was responsible for crossing the water to find food sources and spawning. The population of yellowfin in the waters is threatened and getting smaller at length due to the degradation of the fishing ground and uncontrolled hunting. The efforts to maintain the potential of yellowfin by calculating the size composition of catches based on time (temporal) and catching area (spatial), these can be a steps in reducing the level of utilization of yellowfin that are not yet feasible to capture (illegal size) on a large scale and in order to be able to determine the right type of fishing equipment. The methods in this study includes the collection of primary and secondary data, as well as the analysis of catches based on the composition of the length to determine the fishing ground of yellowfin. Determination of the yellowfin fishing ground spatially and temporally can be interpreted in the map of the fishing ground. Optimization of yellowfin catching was more effective in the waters of Aceh Island, Indian Ocean and Rondo Island waters.
\end{abstract}

Keywords: Aceh province, fishing ground, Thunnus albacares, yellowfin tuna 


\section{PENDAHULUAN}

Potensi sumberdaya madidihang merupakan salah satu jenis ikan yang bernilai ekonomis penting. Madidihang termasuk dalam kelompok jenis pelagis besar, dengan siklus hidupnya berada di perairan tropis dan sub-tropis. Kelompok ikan ini beruaya pada lintas perairan untuk mencari sumber makanan dan melakukan pemijahan. Menurut Nakamura (1969) menyatakan bahwa penyebaran madidihang di suatu wilayah perairan dibagi menjadi dua kelompok yaitu kelompok penyebaran sumberdaya madidihang secara horizontal atau penyebaran berdasarkan letak geografis perairan dan kelompok penyebaran madidihang secara vertikal atau penyebaran madidihang menurut kedalaman wilayah perairan.

Sebagai jenis sumberdaya ikan yang bernilai ekonomis penting, populasi madidihang di perairan terancam mengalami degradasi, akibat pemburuan yang tidak terkontrol, sehingga berdampak terhadap jumlah populasi madidihang yang terdapat di perairan Provinsi Aceh. Meningkatnya aktivitas penangkapan tuna madidihang di perairan berdampak terhadap siklus biologis dan terhadap ukuran hasil tangkapan yang semakin kecil (Bahri et al. 2016). Keberadaan ikan madidihang dewasa dengan sendirinya akan terus mengalami degradasi penurunan stok akibat aktivitas laju tangkap yang tidak terkontrol. Dengan demikian diperlukan upaya-upaya pelestarian ikan madidihang untuk menjaga potensi sumberdaya tetap terjaga dengan baik. Salah satu upaya dalam menjaga sumberdaya ikan madidihang di perairan Provinsi Aceh yaitu dengan cara menghitung komposisi ukuran hasil tangkapan berdasarkan waktu (temporal) dan daerah penangkapan (spasial). Dengan mengetahui waktu dan daerah penangkapan dapat menjadi satu langkah dalam menekan tingkat pemanfaatan sumberdaya madidihang secara besar-besaran dan juga membatasi penggunaan alat tangkap.

Komposisi ukuran panjang hasil tangkapan berdasarkan lokasi dan waktu penangkapan penting untuk diketahui, agar dapat menentukan jenis alat tangkap yang dioperasikan untuk menghindari tertangkapnya ikan-ikan madidihang yang belum layak tangkap (ilegal size). Dengan demikian penentuan daerah penangkapan (fishing ground) madidihang secara spasial dan temporal dapat diinterpretasikan dalam peta daerah penangkapan. Penelitian ini bertujuan untuk mengetahui sebaran ukuran panjang hasil tangkapan madidihang berdasarkan waktu penangkapan dan lokasi penangkapan. Sehingga dapat diketahui pengalokasian alat tangkap yang cocok untuk menghindari tertangkapnya ikan belum layak tangkap (ilegal size).

\section{METODE PENELITIAN}

Penelitian ini dilaksanakan pada bulan Januari hingga Agustus tahun 2017. Lokasi penelitian meliputi wilayah perairan Provinsi Aceh (Gambar 1).

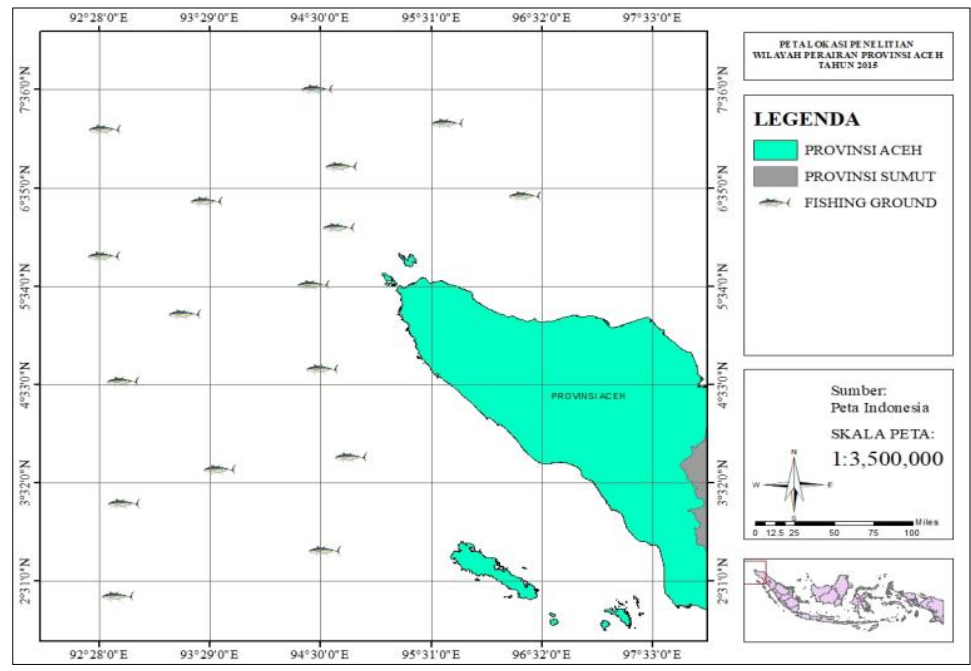

Gambar 1 Peta lokasi penelitian wilayah perairan Provinsi Aceh

Penelitian ini menggunakan dua parameter sampel data, yaitu data primer dan data sekunder, data primer mencakup jumlah hasil tangkapan, ukuran hasil tangkapan, serta lokasi dan waktu 
penangkapan. Sedangkan data sekunder meliputi telaah pustaka untuk mendukung keakuratan data yang dikumpulkan di lapangan. Metode analisis data menggunakan metode chatch per unit effrot (CPUE) untuk mengetahui produksi dan produktivitas hasil tangkapan, berdasarkan lokasi dan waktu penangkapan.

Data produksi ikan madidihang yang diperoleh selama penelitian digunakan untuk menghitung CPUE berdasarkan formula yang telah dijelaskan pada penelitian sebelumnya (Lima et al. 2000) dalam Petrere et al. 2010):

Keterangan:

$$
\text { CPUE } \frac{\text { Chatch }_{\mathrm{i}}}{\text { Effort }_{\mathrm{i}}} \ldots \ldots . . . . \mathrm{ii}
$$

CPUE

Catch $_{i}$ Effort $_{i}$
: Hasil tangkapan per upaya penangkapan (kg/trip) dalam bulan ke- $i$

: Hasil tangkapan $(\mathrm{kg})$ dalam bulan $\mathrm{ke}-i$

: Upaya penangkapan (trip) bulan ke- $i$

Nilai CPUE kemudian disajikan dalam bentuk garfik berdasarkan sebaran jumlah (CPUE) setiap bulan pada lokasi penangkapan ikan tuna madidihang. Dengan melihat hasil tangkapan dapat diketahui fluktuasi hasil tangkapan berdasarkan waktu (temporal) dan lokasi/daerah penangkapan ikan (spasial). Komposisi hasil tangkapan ikan madidihang dianalisis secara deskriptif untuk melihat kisaran panjang ukuran ikan yang tertangkap pada masing-masing lokasi dan waktu penangkapan. Sedangkan untuk mengetahui sebaran ukuran panjang hasil tangkapan dianalisi dengan metode sebaran frekuensi ukuran panjang ikan yang tertangkap berdasarkan lokasi dan waktu penangkapan.

Pengelompokan hasil tangkapan madidihang layak tangkap dan tidak layak tangkap dilakukan dengan mengelompokan hasil tangkapan madidihang berdasarkan ukuran panjang, yaitu ukuran panjang madidihang layak tangkap memiliki panjang cagak sudah mencapai $(>120 \mathrm{~cm})$. Sebaliknya ukuran ikan madidihang belum layak tangkap memiliki panjang cagak kurang $(\leq 120 \mathrm{~cm})$ (Tabel 1). Selanjutnya hasil tangkapan madidihang dikelompokkan berdasarkan daerah penangkapan (spasial) dan waktu penangkapan (temporal) dan dianalisis secara deskriptif. Berdasarkan analisis pada masing-masing variabel dapat diketahui hasil tangkapan madidihang layak tangkap dan tidak layak tangkap.

Struktur ukuran madidihang yang tertangkap dianalisis secara deskriptif, yaitu dengan membandingkan sebaran individu dalam histogram berdasarkan musim dan waktu penangkapan. Ukuran pertama kali matang gonad ikan madidihang dianalisis untuk menentukan ukuran layak tangkap. Ukuran ikan layak tangkap adalah ukuran ikan yang lebih besar dari ukuran panjang ikan saat pertama kali matang gonad (length at first maturity $=\mathrm{Lm}$ ).

Tabel 1 Kriteria ukuran panjang hasil tangkapan ikan madidihang layak tangkap dan tidak layak tangkap

\begin{tabular}{ccc}
\hline Keterangan & $\begin{array}{c}\text { Layak tangkap } \\
(\mathrm{cm})\end{array}$ & $\begin{array}{c}\text { Tidak layak tangkap } \\
(\mathrm{cm})\end{array}$ \\
\hline Ukuran panjang ikan & $\geq 120 \mathrm{~cm}$ & $\leq 120$ \\
\hline
\end{tabular}

Sumber: Bahri S (2015), dimodifikasi.

Jumlah hasil tangkap ikan madidihang selanjutnya dianalisis komposisi jumlah persentase hasil tangkapan berdasarkan waktu dan lokasi. Dari hasil analisis tersebut dapat diketahui masing-masing persentase madidihang yang tertangkap selama bulan Januari-Agustus 2017.

Persamaan untuk menentukan jumlah persentase hasil tangkapan layak tangkap dan tidak layak tangkap menggunakan persamaan sebagai berikut:

Keterangan:

$$
\text { Ps } \frac{X \mathrm{i}}{X i} \ldots \ldots . . .100 \%
$$

Ps : persentase

Lt : layak tangkap

Tl : tidak layak tangkap 
Dengan mengetahui persentase komposisi hasil tangkapan tuna madidihang, maka dapat ditentukan daerah penangkapan serta waktu penangkapan ikan madidihang yang memiliki ukuran layak tangkap (ilegal size).

\section{HASIL DAN PEMBAHASAN}

Produktivitas hasil tangkapan madidihang layak tangkap pada delapan (8) daerah penangkapan menunjukkan bahwa nilai produktivitas $C P U E$ tertinggi terdapat di perairan Pulau Aceh dengan jumlah ikan layak tangkap sebanyak 86 ekor. Sebaliknya nilai $C P U E$ terendah terdapat di perairan Selat Malaka, yaitu sebanyak 13 ekor. Produktivitas CPUE ikan madidihang belum layak tangkap yang termasuk kategori tinggi terdapat di perairan Selat Malaka yaitu 71 ekor, dan terendah di perairan Pulau Rondo dan perairan Sabang, sebanyak 39 ekor. Jumlah hasil tangkapan ikan madidihang layak tangkap dan tidak layak tangkap disajikan pada (Gambar 2).

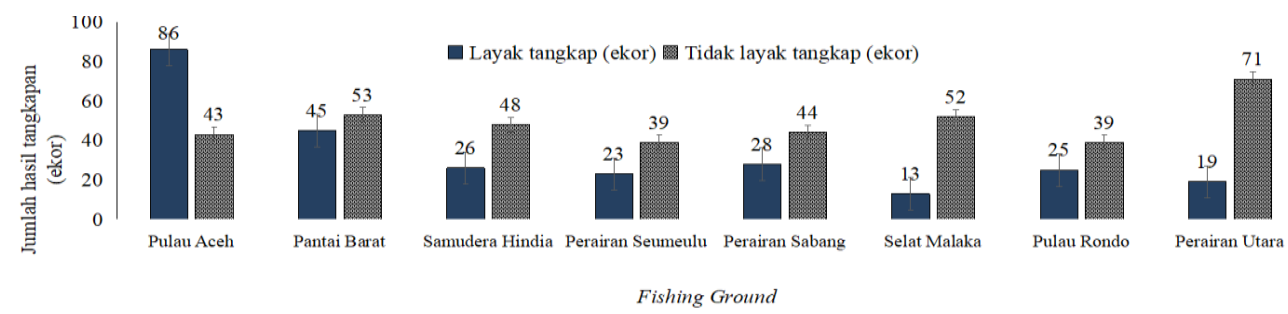

Gambar 2 Jumlah hasil tangkapan ikan madidihang layak tangkap secara spasial bulan Januari-Agustus 2017

Ikan pada umumnya beruaya menuju daerah yang kaya akan nutrien dan sumber makanannya, terutama di dekat pantai dan daerah penaikan massa air (upwelling). Rumpon memiliki daya tarik yang kuat terhadap ikan untuk berkumpul di sekitarnya, sehingga pergerakan ruaya alamiahnya akan terganggu, terutama jika jumlah rumpon yang dipasang di perairan terlalu banyak. Perairan di sekitar rumpon laut dalam umumnya tidak produktif karena posisinya yang jauh dari daratan (Marsac et al. 2000).

Meningkatnya produksi ikan layak tangkap di perairan Pulau Aceh mengambarkan bahwa perairan Pulau Aceh merupakan areal yang berbatasan langsung dengan Samudera Hindia, dan merupakan jalur migrasi tuna-tuna madidihang di wilayah perairan Provinsi Aceh. Dengan demikian peningkatan produksi pada perairan tersebut dapat dijadikan sebagai daerah penangkapan ikan madidihang yang potensial. Bahri et al. (2016) melaporkan bahwa perairan Pulau Aceh, Pulau Rondo dan Samudera Hindia merupakan daerah penangkapan ikan madidihang yang potensial pada musim barat yaitu pada bulan Januari-Februari. Menurunnya CPUE di perairan Selat Malaka juga dipengaruhi oleh daerah penangkapan yang berada di perairan tersebut sudah mengalami over fishing, sehingga mempengaruhi persentase produksi jumlah hasil tangkapan ikan layak tangkap (Gambar 3).

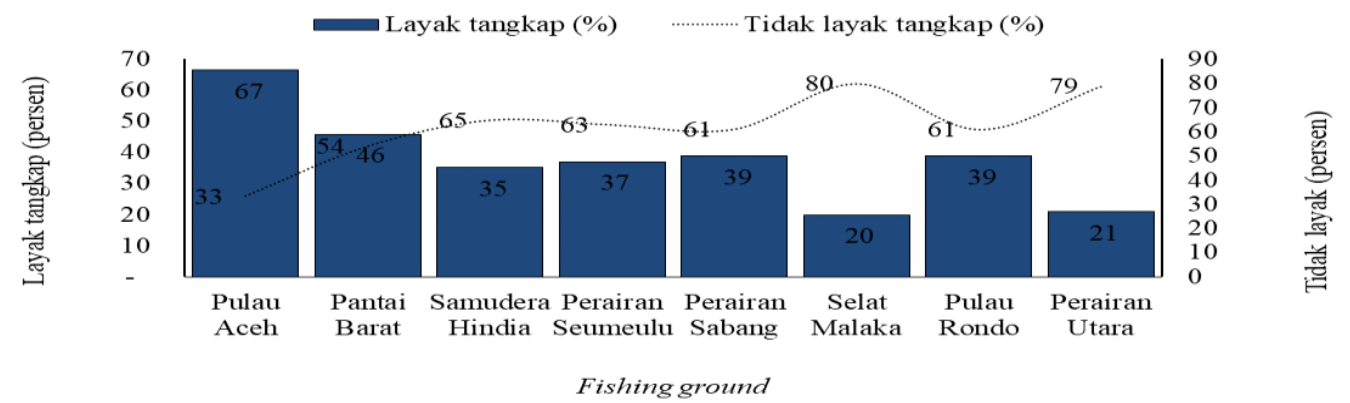

Gambar 3 Persentase komposisi hasil tangkapan ikan madidihang bulan Januari-Agustus 2017

Produktivitas CPUE madidihang yang tertangkap pada delapan lokasi terdapat pola yang cenderung bervariasi. Produktivitas tertinggi terdapat pada wilayah perairan Pulau Aceh, Pantai Barat, dan Pulau Rondo. Sebaliknya Produktivitas CPUE ikan belum layak tangkap, kategori tinggi terdapat di Perairan Utara, Selat Malaka, dan Perairan Sabang. Produktivitas CPUE jumlah ikan madidihang disajikan pada (Gambar 4). 


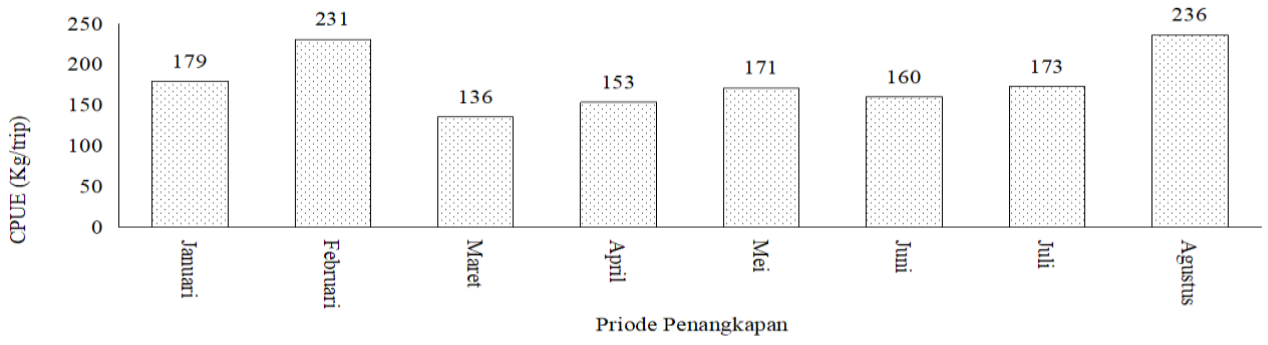

Gambar 4 Produktivitas jumlah ikan madidihang yang tertangkap selama bulan Januari-Agustus 2017

\section{Komposisi Ukuran Panjang Hasil Tangkapan}

Komposisi hasil tangkapan madidihang yang tertangkap selama bulan Januari hingga Agustus menunjukkan ukuran panjang yang bervariasi. Hasil tangkapan pada bulan Januari-Agustus (musim barat, musim peralihan dan musim timur) menunjukkan ukuran bervariasi yaitu berkisar antara 1.21 $\mathrm{cm}-1.36 \mathrm{~cm}$. Komposisi ukuran panjang ikan layak tangkap, bulan Januari-Februari (musim barat) berkisar $128 \mathrm{~cm}$. Selanjutnya bulan Maret-Mei (musim peralihan), ukuran panjang hasil tangkap layak tangkap berkisar $1.30 \mathrm{~cm}-1.36 \mathrm{~cm}$. Memasuki bulan Juni-Agustus (musim timur) ukuran panjang ikan layak tangkap berkisar antara $121 \mathrm{~cm}-135 \mathrm{~cm}$. Komposisi ukuran panjang madidihang layak tangkap dan tidak layak tangkap pada bulan Januari-Agustus disajikan pada (Gambar 5).

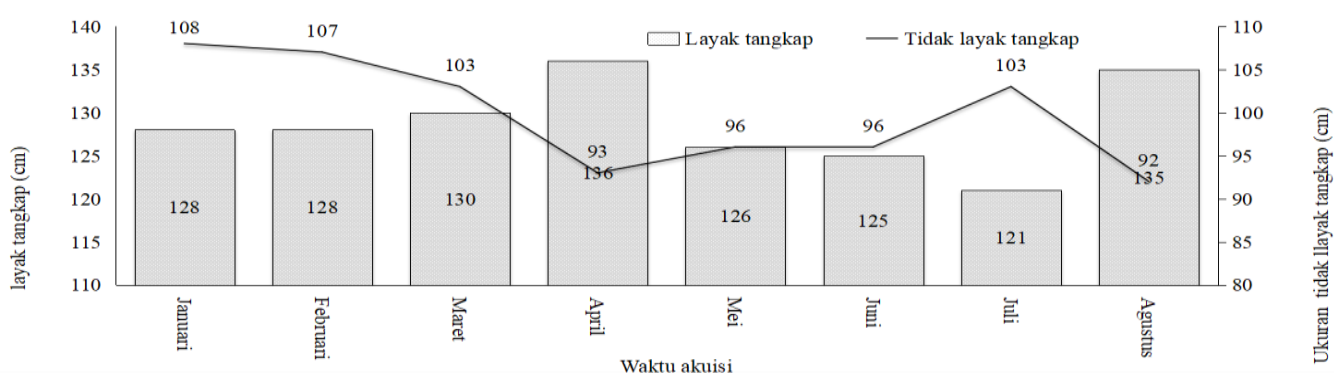

Gambar 5 Komposisi ukuran panjang madidihang yang tertangkap pada bulan Januari-Agustus 2017

Berdasarkan hasil komposisi ukuran panjang hasil tangkapan madidihang selama bulan Januari-Agustus, terlihat trend ukuran yang semakin mengecil, terjadi pada bulan Mei-Juli. Kantun et al. (2014) menyatakan bahwa terdapat kecenderungan bahwa ukuran tuna madidihang yang tertangkap berdasarkan waktu penangkapan bulanan memperlihatkan pola penurunan mulai Juli-Oktober, selain itu ukuran terkecil yang tertangkap berada pada ukuran larva $(<40 \mathrm{~cm})$ dan juvenil $(>40 \mathrm{~cm})$. Sementara ukuran terbesar yang tertangkap adalah ukuran mijah atau ukuran layak tangkap.

Komposisi hasil tangkapan madidihang belum layak tangkap selama bulan Januari sampai Agustus menunjukkan ukuran panjang yang bervariasi. Hasil tangkapan pada bulan Januari-Februari (musim barat) yaitu $107 \mathrm{~cm}-108 \mathrm{~cm}$. Musim peralihan bulan Maret-Mei ukuran panjang hasil tangkapan madidihang belum layak tangkap cenderung lebih kecil dibandingkan pada musim barat, yaitu berkisar antara $93 \mathrm{~cm}-103 \mathrm{~cm}$. Namun pada bulan Juni-Agustus (musim peralihan) ukuran madidihang tidak layak tangkap tidak mengalami peningkatan pada ukuran panjang yaitu $92 \mathrm{~cm}-103$, ukuran panjang hasil tangkap pada musim timur terdapat trend yang mirip dengan musim peralihan. Meningkatnya jumlah ikan madidihang belum layak tangkap disebabkan oleh faktor keberadaan ikan madidihang dewasa yang melakukan swimming layer pada kedalaman 50-150 meter dari permukaan perairan. Sedangkan ikan madidihang yang tergolong ke dalam kelompok juvernil suka mencari sumber makanan di lapisan atas. Gambar 6 menunjukkan bentuk fisik madidihang dewasa dengan panjang mínimum $120 \mathrm{~cm}$. 


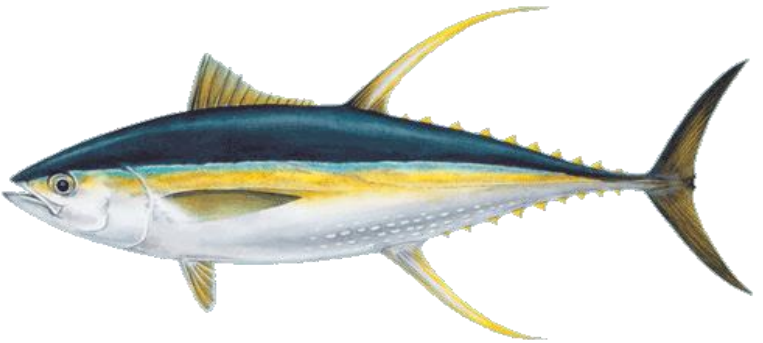

Ukuran panjang layak tangkap (Fork Length)120 cm atau bobot $25 \mathrm{~kg}$
Nama indonesia:

Sirip kuning/Madidihang

Nama Latin:

Thunnus albacares

Nama Inggris:

Yellowfin tuna

Gambar 6 Bentuk fisik madidihang dewasa dengan panjang minimal layak tangkap $120 \mathrm{~cm}$

Alonso (et al. 2005) menyatakan bahwa aktivitas penangkapan pada level permukaan cenderung tertangkap ikan-ikan madidihang yang belum layak tangkap (ilegal size) yaitu berkisar antara $50 \mathrm{~cm}$ $90 \mathrm{~cm}(F L)$ yang bermigrasi dengan cara berenang di atas permukaan perairan. Di sisi lain, longliner menangkap tuna dewasa pada $(60-120 \mathrm{~cm})$ berada di perairan yang lebih dalam. Persentase ukuran madidihang layak tangkap dan tidak layak tangkap bulan Januari-Agustus disajikan pada (Gambar 7).

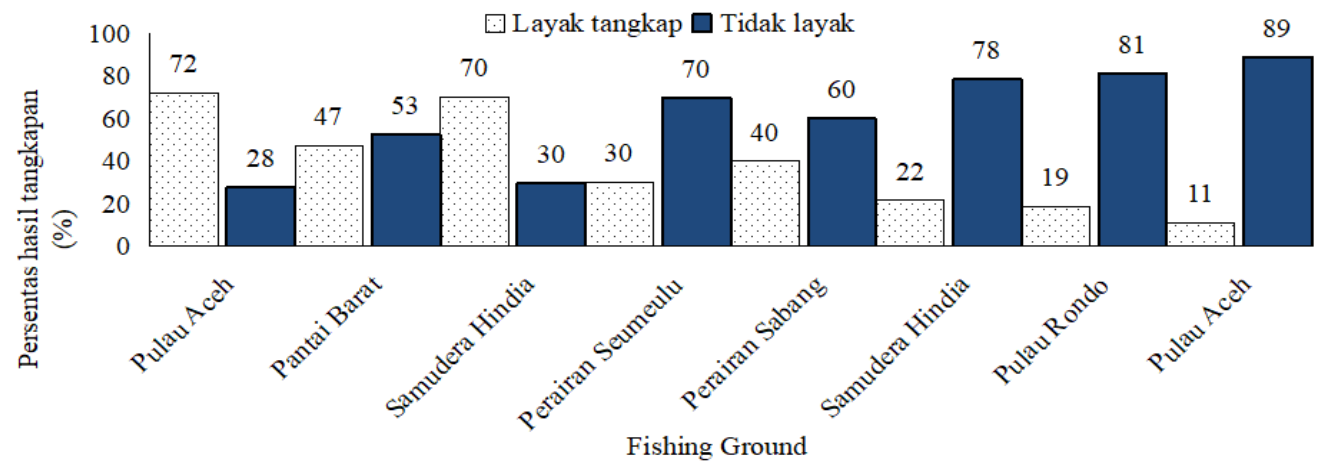

Gambar 7 Komposisi persentase ukuran panjang rata-rata ikan madidihang yang tertangkap bulan Januari-Agustus 2017

\section{Persentase Jumlah Hasil Tangkapan}

Persentase jumlah ikan layak tangkap dan tidak layak tangkap priode bulan Januari-Agustus didominasi oleh komposisi hasil tangkapan madidihang belum layak. Persentase ikan layak tangkap hanya terdapat pada bulan Januari-Maret. Namun pada bulan April-Agustus, persentase ukuran ikan belum layak tangkap mengalami peningkatan secara signifikan. Menurunya persentase jumlah hasil tangkapan layak tangkap sangat dipengaruhi oleh keberadaan madidihang yang bermigrasi pada bulan tesebut. Ikan tuna madidihang dewasa pada umumnya bermigrasi ke perairan yang lebih dalam untuk mencari sumber makanan dan melakukan pemijahan. Persentase hasil tangkapan layak tangkap pada bulan Januari sebanyak 65\%, Februari 55\%, dan Maret 60\%. Namun sebaliknya persentase hasil tangkap tidak layak tangkap pada bulan April-Agustus mengalami peningkatan secara drastis, yaitu berkisar antara $61 \%$ - 84\%. Komposisi persentase hasil tangkapan madidihang ini menunjukkan bahwa keberadaan ikan madidihang yang tertangkap di perairan Provinsi Aceh sangat dipengaruhi oleh perbedaan musim yang terjadi akibat perubahan kondisi lingkungan secara dinamis (Tabel 2).

\section{Daerah Penangkapan Madidihang}

Daerah penangkapan (fishing ground) tuna madidihang selama bulan Januari-Agustus 2015 terdapat delapan lokasi yang menjadi target operasi penangkapan madidihang. Namun berdasarkan jumlah produksi hasil tangkapan, hanya terdapat dua wilayah perairan yang mempunyai tingkat produktivitas jumlah hasil tangkapan meningkat, yaitu wilayah perairan Seumeulu, Pulau Aceh, dan Pulau Rondo. Berdasarkan komposisi ukuran panjang ikan layak tangkap dan ukuran tidak layak 
tangkap, perairan Pulau Aceh dan Pulau Rondo menunjukkan komposisi yang didominasi oleh ukuran ikan layak tangkap (legal size) dengan panjang rata-rata hasil tangkapan $128 \mathrm{~cm}$. Sebaliknya perairan Seumeulu didominasi oleh ikan tidak layak tangkap. Walaupun kedua wilayah perairan tersebut menunjukkan jumlah produksi yang meningkat, wilayah perairan seumeulu secara biogis belum layak dapat dikategorikan daerah potensial penangkapan ikan madidihang. Peta daerah penangkapan ikan madidihang disajikan pada (Gambar 8).

Tabel 2 Komposisi persentase jumlah hasil tangkapan ikan madidihang bulan Januari-Agustus 2017

\begin{tabular}{|c|c|c|c|c|c|c|}
\hline \multirow{2}{*}{ Bulan } & \multicolumn{2}{|c|}{ Jumlah ikan tertangkap } & \multirow{2}{*}{$\begin{array}{l}\text { Jumlah hasil } \\
\text { tangkapan }\end{array}$} & \multicolumn{2}{|c|}{ Persentase hasil tangkap } & \multirow{2}{*}{$\begin{array}{c}\text { Persentase } \\
(\%)\end{array}$} \\
\hline & layak tangkap & tidak layak & & layak tangkap & tidak layak & \\
\hline Januari & 54 & 29 & 83 & 65 & 35 & 100 \\
\hline Februari & 53 & 43 & 96 & 55 & 45 & 100 \\
\hline Maret & 35 & 23 & 58 & 60 & 40 & 100 \\
\hline April & 17 & 39 & 56 & 30 & 70 & 100 \\
\hline Mei & 25 & 39 & 64 & 39 & 61 & 100 \\
\hline Juni & 15 & 37 & 52 & 29 & 71 & 100 \\
\hline Juli & 18 & 48 & 66 & 27 & 73 & 100 \\
\hline Agustus & 12 & 64 & 76 & 16 & 84 & 100 \\
\hline
\end{tabular}

Menurut Kunarso et al. (2005) menyatakan bahwa untuk menentukan fishing ground tuna tidak hanya berdasarkan lokasi upwelling. Dalam hal ini perlu juga memahami bioekologi jenis-jenis tuna, lima hal yang terpenting yaitu daerah pemijahan, jalur migrasi, jenis makanan, suhu lingkungan yang disukai, dan kedalaman lapisan renangnya. Keberadaan madidihang sangat dipengaruhi oleh faktor-faktor lingkungan yang merupakan habitat hidupnya, hal ini sangat dipengaruhi oleh faktor musim yang terjadi perubahan secara berskala. Menurut Komisi Tuna Samudra Hindia Indian ocean tuna commission IOTC (2015), status stok tuna mata besar di Samudra Hindia masih dalam kondisi aman (kurang tangkap), sehingga pemanfaatan spesies ikan ini masih bisa dimanfaatkan secara optimal. Jumlah hasil tangkapan yang terjadi pada bulan April-Agustus musim peralihan mengalami penurunan. Daerah penangkapan madidihang dapat difokuskan pada wilayah perairan Samudera Hindia yang mempunyai stok sumberdaya madidihang melimpah.

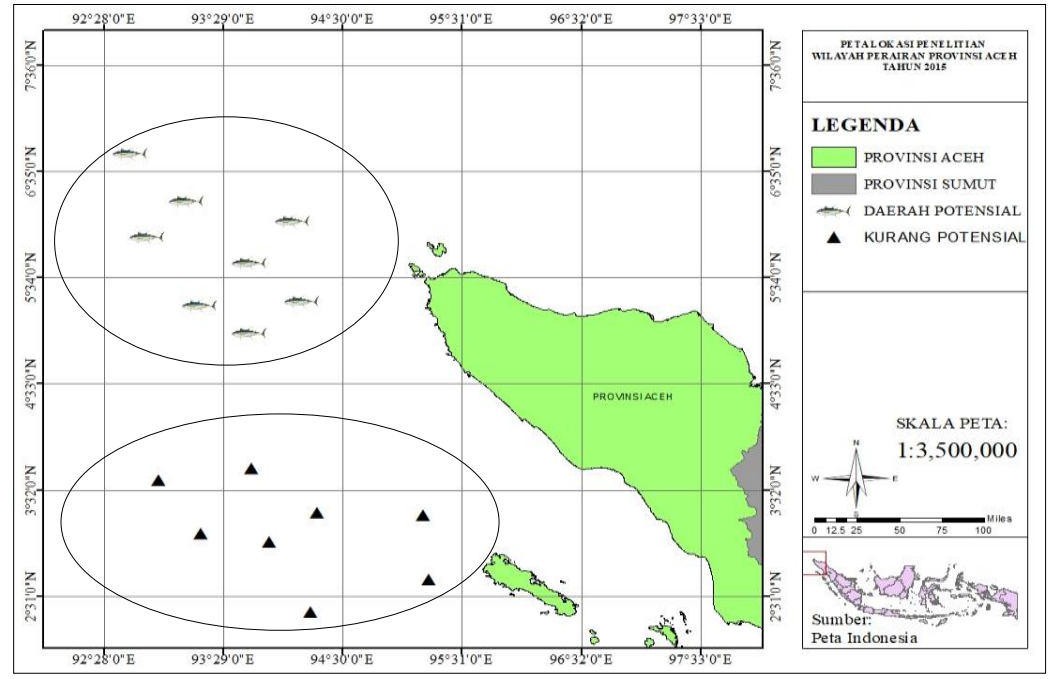

Gambar 8 Peta daerah petensial penangkapan ikan madidihang di perairan Provinsi Aceh tahun 2017

Menurunnya jumlah hasil tangkapan madidihang layak tangkap pada bulan April-Agustus diduga dipengaruhi oleh faktor musim. Pada bulan Maret-Mei wilayah perairan Provinsi Aceh sudah 
memasuki musim peralihan dari barat ke timur. Sedangkan pada bulan Juni-Agustus perairan Provinsi Aceh memasuki musim timur. Hal tersebut diduga akan mempengaruhi aktivitas penangkapan, selain faktor perubahan musim, kondisi cuaca, serta serta tinggi curah hujan yang menyebabkan nelayan tidak dapat melakukan aktivitas penangkapan di wilayah perairan tersebut.

Selain faktor kondisi perubahan musim yang berganti setiap tahun, umumnya nelayan yang menangkap tuna madidihang di Provinsi Aceh masih belum memiliki kapasitas armada yang mamadai darri segi ukuran kapal dan teknologi penangkapan. Nelayan pada umumnya masih menggunakan kapal-kapal motor dengan ukuran 20-35 GT.

\section{KESIMPULAN DAN SARAN}

\section{Kesimpulan}

Berdasarkan hasil penelitian, dapat disimpulkan bahwa terjadinya pola perubahan musim penangkapan ikan madidihang yang terjadi secara temporal menunjukkan pola distribusi ikan madidihang di perairan Provinsi Aceh terdapat trend daerah penangkapan (fishing ground) yang selalu mengalami perubahan setiap bulan. Optimasi usaha penangkapan ikan madidihang lebih efektif dilakukan di daerah penangkapan madidihang di perairan Pulau Aceh, Samudera Hindia, dan perairan Pulau Rondo. Hal ini sangat penting untuk menghindari hasil tangkapan ikan madidihang belum layak tangkap.

\section{Saran}

Optimasi usaha penangkapan madidihang di Perairan Provinsi Aceh, Perlu dilakukan upaya pemataan daerah penangkapan untuk menhindari tertangkapnya tuna-tuna yang belum layak tangkap (ilegal size) dengan memberi ruang penyebaran terhadap populasi madidihang yang semakin mengalami degragadasi akibat meningkat jumlah armada dan teknologi penangkapan.

\section{DAFTAR PUSTAKA}

Alonso C., Arrizabalaga H., Restrepo VR. 2005. Contribution of a chapter on albacore tuna for the revised ICCAT field manual. Collect Vol Sci Pap ICCAT, 58(5):1646-1661.

Kantun W., Mallawa A., Rapi N.L. 2014. Struktur ukuran dan jumlah tangkapan tuna madidihang (Thunnus albacares) menurut waktu penangkapan dan kedalaman di Perairan Mejene Serlat Makasar. Jurnal Saintek Perikanan, 9(2):39-48.

Kunarso K, Hadi S, Ningsih NS. 2005. Kajian lokasi upwelling untuk penentuan fishing ground potensial ikan tuna. ILMU KELAUTAN: Indones J Marine Sci. 10(2):61-67.

Bahri S, Domu Simbolon, Mustaruddin. 2016. Analisis daerah penangkapan ikan madidihang (Thunnus albacares) berdasarkan suhu permukaan laut dan sebaran klorofil-a di Perairan Provinsi Aceh. Jurnal Teknologi Perikanan dan Kelautan 8(1):95-104.

Indian Ocean Tuna Commission. 2015. Report of the 17thSession of the IOTC Working Party on Tropical Tunas (p. 102). IOTC-2015-WPTT17-R.

Lima AC, Freitas CEC, Abuabara MA, Petrere M, Batista VS. 2000. On the standardization of the fishing effort. Acta Amazonica. 30:167-169.

Marsac F, Fonteneau A, Menard F. 2000. Drifting FAD sused in tuna fisheries: an ecological trap? peche thoniere et dispositifs de concentration de poissons. Edition Ifremer. Actes Colloque. 28:36-54. 